IZA DP No. 8522

Cultural Values and Decision to Work of Immigrant Women in Italy

Vincenzo Scoppa

Manuela Stranges

October 2014 


\title{
Cultural Values and Decision to Work of Immigrant Women in Italy
}

\author{
Vincenzo Scoppa \\ University of Calabria \\ and IZA \\ Manuela Stranges \\ University of Calabria
}

\section{Discussion Paper No. 8522 \\ October 2014}

\author{
IZA \\ P.O. Box 7240 \\ 53072 Bonn \\ Germany \\ Phone: +49-228-3894-0 \\ Fax: +49-228-3894-180 \\ E-mail: iza@iza.org
}

Any opinions expressed here are those of the author(s) and not those of IZA. Research published in this series may include views on policy, but the institute itself takes no institutional policy positions. The IZA research network is committed to the IZA Guiding Principles of Research Integrity.

The Institute for the Study of Labor (IZA) in Bonn is a local and virtual international research center and a place of communication between science, politics and business. IZA is an independent nonprofit organization supported by Deutsche Post Foundation. The center is associated with the University of Bonn and offers a stimulating research environment through its international network, workshops and conferences, data service, project support, research visits and doctoral program. IZA engages in (i) original and internationally competitive research in all fields of labor economics, (ii) development of policy concepts, and (iii) dissemination of research results and concepts to the interested public.

IZA Discussion Papers often represent preliminary work and are circulated to encourage discussion. Citation of such a paper should account for its provisional character. A revised version may be available directly from the author. 


\section{ABSTRACT}

\section{Cultural Values and Decision to Work of Immigrant Women in Italy}

We investigate the role of culture in explaining economic outcomes at individual level analyzing how cultural values from the home country affect the decision to work of immigrants in Italy, using the National Survey of Households with Immigrants. Following the "epidemiological approach", we relate the probability of being employed in Italy for immigrant women with the female labor force participation (LFP) in their country of origin, taken as a proxy of cultural heritage and gender role model. Controlling for a number of individual and household characteristics, we show that participation in the labor market is affected both by the culture of females' and by their husband's origin countries. We also show that the relationship between own decisions in the host country and home country LFP cannot be attributed to human capital quality or discrimination and it turns out to be stronger for immigrants that maintained more intense ties with their origin countries. Finally, we investigate to what extent cultural influence is driven by religious beliefs: we find that religion is a key determinant of differences in female labor decisions, but, besides religion, other cultural values exert additional influence.

JEL Classification: $\quad$ Z10, Z13, J10, J15, J16, J20

Keywords: culture, immigration, labor force participation, epidemiological approach, gender, Italy

Corresponding author:

Vincenzo Scoppa

Dipartimento di Economia, Statistica e Finanza

Università della Calabria

Via Ponte Bucci

87036 Arcavacata di Rende (CS)

Italy

E-mail:v.scoppa@unical.it

\footnotetext{
* We would like to thank Francesca Bettio, Maria De Paola, Filippo Domma, Sabrina Giordano, Benedetta Magri, Letizia Mencarini, Michela Ponzo, Mariacristina Rossi, Alessandra Venturini, and seminar participants at the Summer School on "Gender Economics and Society" (ILO and University of Turin, July 2014), and at the University of Calabria for useful comments and suggestions.
} 


\section{Introduction}

The role of culture - that is, the set of preferences, values, attitudes and beliefs transmitted across generations among ethnic, religious and social groups (Guiso, Sapienza and Zingales, 2006) - has been neglected in the economic literature for a long time, both for the relative vagueness of this concept and for the difficulty in empirically identifying causal relationships among cultural and economic variables. A number of recent contributions is filling this gap by showing that culture plays a relevant role in explaining economic outcomes at the individual and at the aggregate level (Fernández, 2011).

In general, it is hard to evaluate whether observed variations in economic or social outcomes across countries or along time are attributable to differences in cultural values since, besides culture, a range of economic and institutional factors tend to differ across time and space.

One recent approach aimed to investigate the causal role of culture is the so-called “epidemiological approach” (Fernández , 2007, 2011; Fernández and Fogli, 2009) that analyzes how economic and social outcomes of immigrants (or their descendants) - coming from countries with different cultural values and beliefs but living in an environment (the host country) with uniform institutional and economic characteristics - are affected by attitudes observed in the home country. This approach exploits the greater "portability" of culture with respect to economic or institutional factors. Thus, the fact that the immigrants in the host country - despite they face the same economic and institutional environment - show economic or social choices related to the behaviors observed in their home country is taken as evidence of the importance of cultural values in defining economic outcomes.

In this paper we follow the epidemiological approach focusing on female labor force participation, a decision that could be strongly affected - beyond economic considerations - by cultural values. The differences among countries of origin may well depend on labor market conditions (wages, technology, type of work, etc.), institutions (taxation, child care availability, etc.) but also on gender role models and the prevalent view of the role of woman in society and how a working woman is perceived by herself, by relatives, the neighbors, the social group of reference, etc.

We use variations in the labor force participation (LFP) rates in the home country to explain individual decisions to work in the country of destination. Controlling for a wide range of individual and household factors, we show that the probability of participation in the labor market of female immigrants is influenced by the cultural values of their home country. This approach is based upon the idea that the country of origin's cultural factors have a long-lasting effect also in the new environment in the destination country.

Our paper is strictly related to Fernández and Fogli (2009) analyzing female labor force participation and fertility of second-generation immigrants in US in relation to the patterns observed in 
their ancestors' countries. As other studies in this field (see below), they refer to United States, which is probably the most important immigration country in the world. We contribute to this field of study by analyzing how cultural values affect female labor participation of foreigners in Italy, which is a recent immigration country.

Other notable differences with respect to the analysis of Fernández and Fogli (2009) are that: (i) we focus on immigrants of first generation instead of second generation, an approach that - as we will discuss - has its specific advantages and disadvantages; (ii) the immigrants in our sample come from a wide range of countries, around 120, while Fernández and Fogli (2009) use only 25 countries, of which 17 are European countries; (iii) we try to disentangle the effects of religious beliefs from other cultural values.

Fernández and Fogli (2009) find that female labor force participation and fertility rates from the origin country of females’ parents (in 1950) affect, respectively, hours of work and number of children of females residing in US in 1970, controlling for a wide range of individual characteristics. Similarly, Antecol (2000) shows that gender gaps among immigrants in labor force participation depend on the corresponding gender gaps in the country of origin, but she does not control for individual variables that could affect the outcome. Using more recent data, Blau, Kahn, Liu and Papps (2013) find evidence of intergenerational transmission of gender roles, in that they show that the fertility and labor supply of second generation female immigrants are positively related to the corresponding rates in their parents' origin country, especially to the mother's origin country, while the educational attainment of males is especially related to the father's origin country. Furthermore, they show the existence of a strong process of assimilation of immigrants to the host country patterns. Gevrek, Gevrek and Gupta (2013) use data of Canadian immigrants and find that the relative female LFP in the country of ancestry is significant in explaining how much second-generation female immigrants work.

In studying the influence of culture on other outcomes, Carroll, Rhee and Rhee (1994) - in one of the first paper relating immigrants' behaviors to their cultural background - find that the areas of origin do not affect savings decisions of immigrants in Canada. Guiso, Sapienza and Zingales (2003) show that trust (and then trade) is affected by religious beliefs, genetic distance between populations and history of wars between countries. In a related paper (Guiso, Sapienza and Zingales, 2006), they find that fertility rates are higher and female employment lower in countries in which people have traditional views about women's role. Giuliano (2007) finds that living arrangements of young individuals in the US follow the patterns observed in their ancestors' countries. Alesina and Giuliano (2011) show that political participations of immigrants in 32 destination countries depend on the strength of family ties in their origin countries. In a different context, Fisman and Miguel (2007) show that the propensity of UN diplomats to commit parking violations in New York depends positively on the corruption levels of their countries.

Our analysis is based on data from the "Italian Statistics on Income and Living Conditions of Households with Foreigners” (ISTAT, 2009), covering about 6,000 households with at least one 
foreign member, for over 15,000 observations. This survey provides detailed information on individuals’ demographic and socio-economic characteristics.

Italy is a country of relative recent immigration flows characterized by a variety of foreignnational groups (coming from more than 100 countries) whose composition has changed considerably during the last decade. At the end of 2009, foreigners resident in Italy were about 4,235,000, equivalent to about 7 percent of the total population.

Controlling for a number of individual and household characteristics (education, age, years of residence in Italy, geographical areas, number of children, husband's education, age, income, etc.), we show that participation in the labor market is affected both by the culture of females' origin country and by their husbands' one. A woman coming from a country with labor force participation 10 percentage points more than the average has a higher probability of being employed in Italy of about 5 p.p. For married women, the female labor force participation rate in the husband's country has a similar or even higher impact. We verify that these effects do not depend on the quality of human capital or per capita income of the origin country. We show that the link between labor participation decisions in the host country and home country LFP is strong only for those planning to go back to their origin countries, reinforcing the explanation based on culture.

Our findings are robust to different definition of the main variables, different samples and different estimation methods. Finally, we investigate to what extent cultural influence is driven by religious beliefs: we find that religion is a key determinant of differences in female employment decisions, but, controlling for religious denominations, we show that other cultural values exert additional influence.

The paper is structured as follows. In Section 2 the data and the main characteristics of the sample are described. In Section 3 we present the methodology used to estimate empirically the impact of culture on economic outcomes and show our main findings. In Section 4 we verify, alternatively, if the quality of human capital, discrimination or some other factors could drive our results. In Section 5 a number of robustness checks are carried out. In Section 6 we investigate the role of religion. Concluding remarks follow in Section 7.

\section{Data and Descriptive Statistics}

Our analysis is based on data from the 2009 "Statistics of Income and Living Conditions (SILC) of Households with Foreigners”, the largest survey of immigrant population ever conducted in Italy. This survey covers 6,014 households with at least one foreign member resident in Italy, for a total number of over 15,036 observations (61.5\% of which aged 15 and over).

The survey, conducted by the Italian National Institute for Statistics (ISTAT), is comparable with the standard EU-SILC on the Italian (and other European countries) resident population. It 
provides detailed information on foreigners' working and personal characteristics, including country of origin, occupation, education, family's structure, presence of children, health status, and so on.

Since we are interested in labor force participation, we keep only women whose age range from 20 to 60 years, ${ }^{1}$ obtaining a sample of 5,254 observations. In the population of immigrants, women and men have almost equal representation, being women 51\% at the end of 2009 .

The values of female LFP for each country has been taken from International Labor Organization (ILO) database of Labor Statistics, which provides multiple datasets with annual labor market statistics for almost all the countries in the world. In our main specifications we use the labor force participation rate in the country of origin averaged over the years 1980-1989. In addition, since cultural values tend to evolve slowly, as a robustness check we use the average values of female labor force participation in the period 1990-1999 and in the period 2000-2009. ${ }^{2}$

Summary statistics of the variables used in the analysis are reported in Table 1 . About $53 \%$ of the females in our sample are employed and $69 \%$ are in the labor force. ${ }^{3}$ Our sample females come from 118 different countries. The female LFP in the origin country is on average $48 \%$ with a standard deviation (SD) of $0.12 .^{4}$

The immigrants in the sample are on average 37 years old, their educational level - measured as number of years of education - is on average 10.8 years; ${ }^{5}$ about $51 \%$ of them are married $^{6}$ with an average number of dependent children living in the household equal to 0.96. They have spent on average 10.4 years in Italy. Almost 43\% of them lives in the Northern regions, 20\% lives in the Centre of Italy, while remaining $37 \%$ lives in the Southern area. ${ }^{7}$ About $41 \%$ lives in large cities (approximately, with a population of more than 50,000 inhabitants) and 16\% live in small cities (less than 10,000 inhabitants). General health status of immigrants (self-assessed in 5 categories ranging from "very bad" to "very good") is rather good: 83\% of them declare a good or very good health. The average education of the partners of our sample females is 10.3 , their age is 41 years and their income is 16,375 euros.

\footnotetext{
${ }^{1}$ Retirement age in Italy is 65 years for men and 62 for women. Anyway, we cut age at 60 in order to avoid distorted results resulting from early retirement.

${ }^{2}$ Spearman's rank correlation coefficients among these three variables range between 0.75 and 0.91 .

${ }^{3}$ Participation in the labor market of immigrants on the whole is higher in comparison to the native population: in 2009 foreigners residing in Italy had a labor participation rate equal to $72.7 \%$, in comparison to $61.6 \%$ of the natives (Istat, 2011).

${ }^{4}$ At country level, considering the countries with at least 15 immigrants in our sample, the average LFP is $48 \%$, $\mathrm{SD}$ is 0.16 , ranging from the lowest value of Algeria (9\%) to the highest of Ghana (78\%).

${ }^{5}$ The dataset contains information about the highest level of formal qualification obtained by individuals. We recode this variable by assigning the number of years of schooling to each level. So "No qualification" was put equal to 0; "No title but can read and write" = 3 years of schooling; "Primary (Elementary) school" = 5 years of schooling; "Lower secondary education (Junior)" = 8; "Upper secondary education" = 13; "Post-secondary notcollege" = 15; "College (University diploma, college, Degree or Master, Master degree)" = 18; "PhD" = 21.

${ }^{6}$ Marital status is measured through a dummy variable which takes the value of 1 if the individual is married or cohabiting and 0 otherwise (i.e., never married, widowed, separated or divorced).

${ }^{7}$ The regions included in North West are: Piedmont, Valle d'Aosta, Liguria and Lombardy; in North East: Trentino, Veneto, Friuli-Venezia Giulia and Emilia-Romagna; in the Centre: Tuscany, Umbria, Marche and Lazio; in the South: Abruzzi, Molise, Campania, Apulia, Basilicata and Calabria; in the Island: Sicily and Sardinia.
} 
We also consider a number of variables measuring human capital in the home country: average years of schooling, per capita income, and quality of education (scores obtained by students in standardized international tests). Finally, we consider the major religion professed in each country. The details of the latter variables will be provided below.

Table 1. Descriptive Statistics

\begin{tabular}{|c|c|c|c|c|c|}
\hline Variable & Mean & Std. Dev. & Min & Max & Obs \\
\hline Employed & 0.530 & 0.499 & 0 & 1 & 5254 \\
\hline In Labor Force & 0.693 & 0.461 & 0 & 1 & 5254 \\
\hline Female LFP in Home Country & 0.480 & 0.123 & 0.087 & 0.883 & 5254 \\
\hline Age & 36.974 & 10.110 & 20 & 60 & 5254 \\
\hline Age Squared & 1469.281 & 788.312 & 400 & 3600 & 5254 \\
\hline Years of Residence & 10.411 & 8.571 & 1 & 60 & 5181 \\
\hline Education & 10.826 & 4.271 & 0 & 21 & 5254 \\
\hline Married & 0.509 & 0.500 & 0 & 1 & 5254 \\
\hline Dependent Children & 0.961 & 1.073 & 0 & 7 & 5254 \\
\hline North-West & 0.207 & 0.405 & 0 & 1 & 5254 \\
\hline North-East & 0.219 & 0.414 & 0 & 1 & 5254 \\
\hline Centre & 0.203 & 0.402 & 0 & 1 & 5254 \\
\hline South & 0.198 & 0.398 & 0 & 1 & 5254 \\
\hline Islands & 0.174 & 0.379 & 0 & 1 & 5254 \\
\hline Small City & 0.162 & 0.369 & 0 & 1 & 5254 \\
\hline Medium City & 0.423 & 0.494 & 0 & 1 & 5254 \\
\hline Large City & 0.414 & 0.493 & 0 & 1 & 5254 \\
\hline Good Health & 0.831 & 0.374 & 0 & 1 & 5254 \\
\hline Poor Health & 0.039 & 0.195 & 0 & 1 & 5254 \\
\hline Partner's Education & 10.266 & 4.211 & 0 & 21 & 2482 \\
\hline Partner's Age & 41.100 & 9.403 & 21 & 80 & 2482 \\
\hline Partner's Income & 16.375 & 13.953 & -38.055 & 187.711 & 2482 \\
\hline Female LFP in partner's Country & 0.422 & 0.133 & 0.087 & 0.795 & 2482 \\
\hline Quality Human Capital in Home Country & 4.329 & 0.551 & 3.089 & 5.338 & 4248 \\
\hline Product per Worker in Home Country & 17112.740 & 18801.790 & 481.954 & 105707.8 & 5230 \\
\hline Years of Schooling (avg.) & 9.344 & 2.507 & 0.859 & 13.178 & 4998 \\
\hline Hours worked & 19.006 & 19.263 & 0 & 95 & 5254 \\
\hline Log(Wage) & 6.588 & 0.408 & 4.369 & 8.773 & 2491 \\
\hline Catholic & 0.284 & 0.451 & 0 & 1 & 5254 \\
\hline Muslim & 0.247 & 0.431 & 0 & 1 & 5254 \\
\hline Orthodox & 0.373 & 0.484 & 0 & 1 & 5254 \\
\hline Buddhist & 0.052 & 0.223 & 0 & 1 & 5254 \\
\hline Hindu & 0.023 & 0.151 & 0 & 1 & 5254 \\
\hline Intention to Leave & 0.241 & 0.428 & 0 & 1 & 4987 \\
\hline
\end{tabular}

Sources: ISTAT 2009 "Statistics of Income and Living Conditions (SILC) of Households with Foreigners"; International Labor Organization (ILO) database of Labor Statistics; "International Data on Cognitive Skills” in Hanushek and Woessmann (2009); "Education Attainment Dataset” in Barro and Lee (2013); Penn World Table (Heston, Summers and Aten, 2012); Association of Religion Data Archives.

In Figure 1, focusing only on countries with at least 15 immigrants, we show the relationship between the female employment rate in Italy (averaged by country of origin) and the female LFP in the home country. Clearly, the employment rate of females in Italy is positively correlated to female LFP in the origin country. 


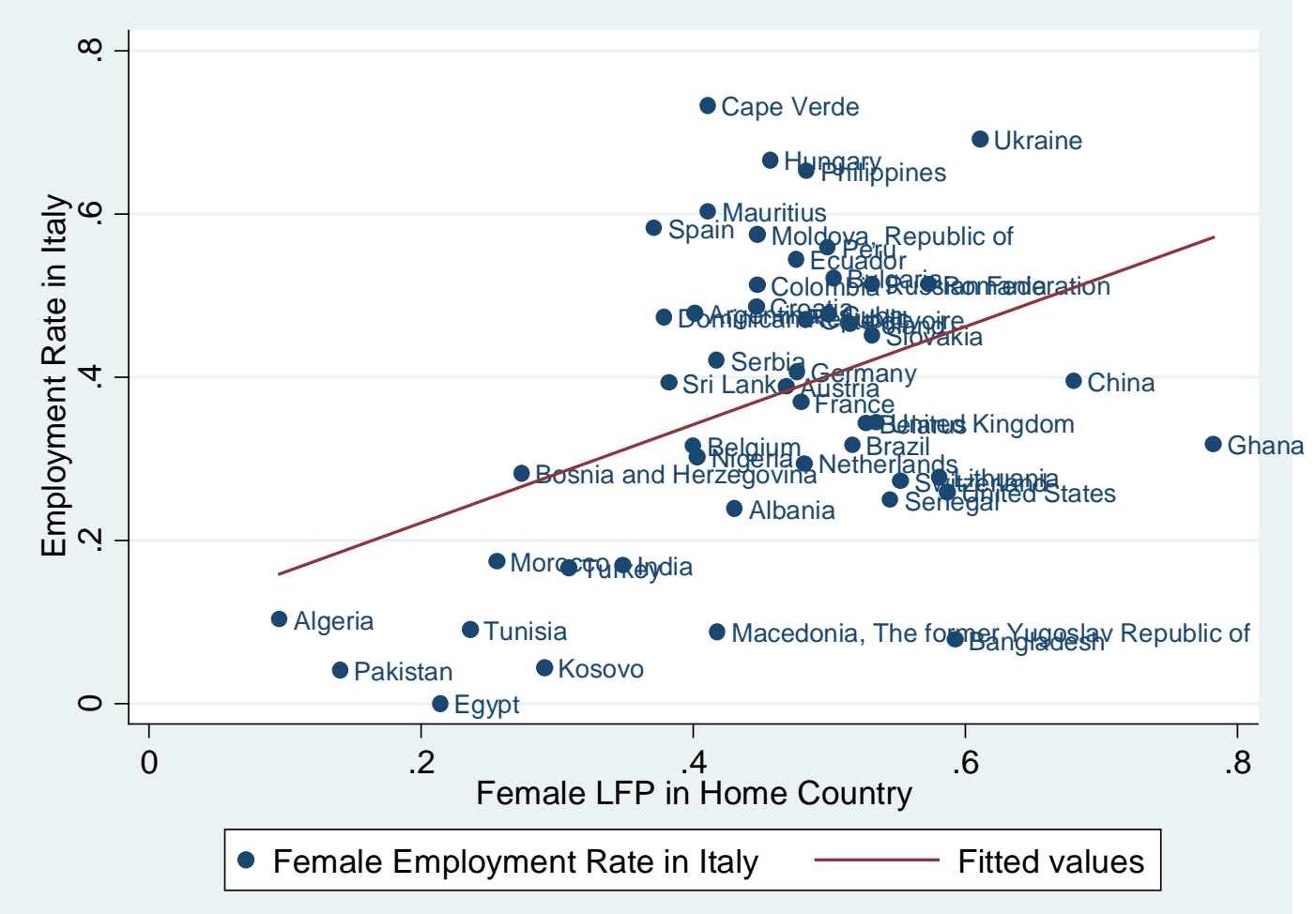

Figure 1. Employment Rate of Immigrant Women in Italy and Female Labor Force Participation in the Home Country.

\section{Female Employment and Cultural Values in the Origin Country: Empirical Findings}

Following Fernández and Fogli (2009), we use the female LFP in the country of origin as a proxy of cultural values. As explained above, using female LFP in the origin country to explain economic outcomes in the host country allows us to capture the effect of culture: when individual characteristics are controlled for and economic and institutional environment of the source country does not matter anymore (since the immigrant does not live there any longer), it is possible to examine if cultural attitudes, beliefs and preferences have an impact on individual behavior.

Some recent studies assessing the effect of culture on economic outcomes focus on second generation immigrants (Fernández and Fogli, 2009; Alesina and Giuliano, 2011). Being Italy a recent immigration country, we use data on first generation immigrants, since second generation immigrants are typically very young and individual data for the phenomenon we are studying are rare. Focusing on first generation immigrants, instead of second generation ones, gives rise to both advantages and disadvantages (cfr. Fernández, 2007). First of all, first generation immigrants typically undergo a shock when they move to the host country and face some remarkable hardships - most prominently, 
language barriers, but also the necessity of adapting to a new environment, search and matching frictions, etc. - that could make particularly hard to find a job. These factors should bias downward the estimate of the impact of culture when using data on first generation. Secondly, while for second generation immigrants the transmission of culture works prevailingly through their relationships with the parents, first generation immigrants are influenced in their cultural values and beliefs not only by parents, but also by their neighbors, friends, schools, etc. From this point of view, the impact of culture should turn out to be stronger for first generation immigrants. Thirdly, related to the above point, by residing in the host country since they were born, second generation immigrants are subject to the exposure to a different culture and to a strong assimilation process with the natives; again, focusing on immigrants of first generation, which are less affected by assimilation, should give a more accurate evaluation of the impact of culture.

To uncover the effect of female LFP in the origin country on the probability of employment of female immigrants in Italy, we estimate the following Probit model:

$$
\operatorname{Pr}\left(\text { Employed }_{i k}=1 \mid X\right)=\Phi\left(\beta_{0}+\beta_{1} \text { Female LFP }_{k}+\beta_{2} X_{i}+\beta_{3} X_{-} \text {Partner }_{i}+\beta_{4} H_{k}\right)
$$

where the dependent variable Employed $_{i k}$ is a dummy taking the value of one if the immigrant $i$ coming from country $k$ is currently employed in Italy (and zero otherwise). This variable if affected by: the female labor force participation in the origin country $k$ of immigrant $i$ ( Female $L F P_{k}$ ); a vector of control variables $X_{i}$ (including individual characteristics: age, age squared, education, married, number of children, length of stay in Italy, area of residence, health status); a vector $X_{-}$Partner $_{i}$ of i's partner's characteristics (education, age, female labor force participation in his home country); a vector $H_{k}$ of variables measuring human capital quality in country $k$. Since LFP is constant for each country of origin, standard errors are allowed for clustering at the country level.

An alternative approach would be to use dummies for each country of origin instead of the variable Female LFP in the home country. As argued by Fernández and Fogli, (2009), the use of LFP is better than using mere dummies for home countries, because the latter do not allow to make explicit why it should matter to be from one ancestry instead of another.

In our main analysis we prefer to use Employed as dependent variable instead of individual Labor Force Participation since the first is less affected by subjective evaluations on unemployment status, job search activities and so on. However, as a robustness check we also use the individual labor force participation status finding very similar results.

Table 2 reports marginal effects of Probit estimates of four specifications. In column (1) we regress Employed on only Female LFP in the home country. We find a remarkable and highly statistically significant effect: 10 percentage points more in the labor participation in the home country 
increases a woman's probability of being employed in the host country of 7.4 percentage points ( $t$ stat=6.19).

Starting from column (2), in order to take into account individual characteristics that could be correlated to Female LFP in the home country, we introduce several control variables to avoid any bias in the estimations because of omitted variables. In column (2) we consider as controls some variables who are predetermined with respect to employment decisions: age, age squared (in order to detect potential non-linear relations), years since migration, health status dummies. We find that age has a positive (concave) effect on the employment probability, years of permanence has no effect and immigrants with better health (results not reported) are more likely to work. With these controls, the impact of Female LFP remains almost the same as in column (1).

In column (3) we control in addition for the educational level, city size and area of residence, to take into account different labor markets and social environments, which greatly varies across Italian regions (with the noteworthy differences between the North and the South of the country). Estimation results reported in column (3) confirm the effect of our interest with an almost unchanged coefficient (0.695) and statistical significance $(t$-stat=6.9). Furthermore, we find that the probability of being employed increases with the educational level (5 more years of education increases of about 6.5 percentage points the probability of finding a job); employment perspectives are higher in Northern regions and in large cities.

In column (4) we control for two important determinants of female labor force participation: marital status and the number of dependent children. As expected, married females are much less likely to work (27 percentage points less) and this probability strongly decreases with the number of dependent children (7.8 p.p. for each child).

It is worthwhile to consider that the new control variables inserted in columns (3) and (4) could be simultaneously determined with the dependent variable and could be themselves, at least in part, the outcome of cultural values. For example, the investment in education of a woman whose culture is averse to female work could be lower and thus her education level would capture a significant part of the effect of culture; similarly, the decision to marry or the number of children are influenced by one's cultural background and may therefore capture part of the effect we are trying to measure. In terms of estimates, the direct influence of culture on control variables would cause a downward bias of the effect of culture on employment participation. Nonetheless, even controlling for these variables we find that Female LFP in the home country has a strong effect on the probability of being employed for women. The coefficient is lower in magnitude but it remains highly statistically significant: two women coming from countries with 10 points of difference in the LFP show a difference in the probability of being employed of about 5.1 percentage points $(t$-stat=5.86). 
Table 2. Female Employment and Cultural Values in the Origin Country. Probit estimates

\begin{tabular}{|c|c|c|c|c|}
\hline & $(1)$ & $(2)$ & (3) & $(4)$ \\
\hline \multirow[t]{2}{*}{ Female LFP in Home Country } & $0.737 * * *$ & $0.742^{* * *}$ & $0.695 * * *$ & $0.509 * * *$ \\
\hline & $(0.119)$ & $(0.116)$ & $(0.101)$ & $(0.087)$ \\
\hline \multirow[t]{2}{*}{ Age } & & $0.040^{* * *}$ & $0.038 * * *$ & $0.066 * * *$ \\
\hline & & $(0.006)$ & $(0.006)$ & $(0.007)$ \\
\hline \multirow[t]{2}{*}{ Age Squared } & & $-0.000 * * *$ & $-0.000 * * *$ & $-0.001 * * *$ \\
\hline & & $(0.000)$ & $(0.000)$ & $(0.000)$ \\
\hline \multirow[t]{2}{*}{ Years of Residence } & & 0.000 & -0.000 & $0.002 * *$ \\
\hline & & $(0.001)$ & $(0.001)$ & $(0.001)$ \\
\hline \multirow[t]{2}{*}{ Education } & & & $0.013^{* * *}$ & $0.010^{* * *}$ \\
\hline & & & $(0.003)$ & $(0.003)$ \\
\hline \multirow[t]{2}{*}{ North-East } & & & 0.008 & 0.016 \\
\hline & & & $(0.022)$ & $(0.020)$ \\
\hline \multirow[t]{2}{*}{ Centre } & & & -0.010 & -0.010 \\
\hline & & & $(0.024)$ & $(0.025)$ \\
\hline \multirow[t]{2}{*}{ South } & & & $-0.060 *$ & $-0.095 * * *$ \\
\hline & & & $(0.032)$ & $(0.030)$ \\
\hline \multirow[t]{2}{*}{ Islands } & & & -0.027 & $-0.061^{*}$ \\
\hline & & & $(0.031)$ & $(0.032)$ \\
\hline \multirow[t]{2}{*}{ Large City } & & & $0.077 * *$ & 0.046 \\
\hline & & & $(0.033)$ & $(0.034)$ \\
\hline \multirow[t]{2}{*}{ Small City } & & & -0.001 & -0.014 \\
\hline & & & $(0.019)$ & $(0.021)$ \\
\hline \multirow[t]{2}{*}{ Married } & & & & $-0.268 * * *$ \\
\hline & & & & $(0.024)$ \\
\hline \multirow[t]{2}{*}{ Children } & & & & $-0.078 * * *$ \\
\hline & & & & $(0.008)$ \\
\hline Observations & 5254 & 5131 & 5131 & 5131 \\
\hline Pseudo R-squared & 0.032 & 0.063 & 0.078 & 0.152 \\
\hline Clusters & 118 & 118 & 118 & 118 \\
\hline
\end{tabular}

Notes: The Table reports marginal effects of Probit estimates (evaluated at the mean values of the explanatory variables in the sample). The dependent variable is Employed. In all regressions starting from column (2) we control for health status dummies (5) (not reported). Standard errors (corrected for heteroskedasticity and robust to clusters at the country of origin level) are reported in parentheses. The symbols ***, **, * indicate that coefficients are statistically significant, respectively, at the 1,5 , and 10 percent level.

An alternative approach to the direct estimate of Female LFP in equation [1] - suggested by Fernández and Fogli (2009, p. 160) - is to estimate country fixed effects. Then, the coefficients on country dummies $\left(\mu_{k}\right)$, measuring the average differences across countries in employment of immigrants, can be saved and put in relationship with the variable Female $L F P_{k}$ in a second-stage regression at country level: $\mu_{k}=\lambda_{0}+\lambda_{1}$ Female $L F P_{k}+\varepsilon_{k}$. We carried out a similar exercise (considering only countries with at least 10 immigrants) finding that Female $L F P_{k}$ is strongly correlated with $\mu_{k}$ (coefficient $=0.56$; t-stat=3.1; obs.: 54) (results not reported to save space).

In Table 3 we focus only on married females (remaining with 2,436 observations) and consider the effect on their employment probability of a number of characteristics of their husbands.

In column (1) of Table 3 we find a positive effect of the partner's education on the probability of being employed for females: 10 more years of education increase the probability of working for the 
wife of about 8 p.p. In contrast, the husband's age has a negative effect on the dependent variable, reducing it of about 1 point for each additional year. In column (2) we include as control the partner's income and we find that when the husband earns a higher income the probability of working for the wife diminishes.

More importantly, both in columns (1) and (2) we find that controlling for husband's characteristics, the effect of culture of the home country continues to be strong (the marginal effect is 0.61), implying an increase of 6 p.p. in the employment probability when labor force participation in the home country increases of 10 points.

In column (3), besides considering the effect of the female LFP in the wife's home country, we include the female LFP in the husband's home country, the latter reflecting the cultural background of the husband. Notwithstanding the two proxies of cultural variables are highly correlated $(\rho=0.79)$ since about $70 \%$ of partners come from the same country, we find that both these effects are positive and highly statistically significant: an increase of 10 points in the female LFP in the husband's country of origin increases of about 5.4 p.p. the probability of being in employment for the wife. This effect is higher in magnitude than the coefficient on LFP of wife's country of origin (1.9 p.p.).

To avoid problems of collinearity in using home country LFP rates of both partners, we build the dummy "Same Country" equal to one when both partners come from the same country and "Different Country" equal to one if they come from different countries. In column (4) we interact the Female LFP (of the common origin country) with the dummy "Same Country" and, separately, wife's and husband's country LFP with the dummy "Different Country". Results show that when the wife and the husband come from the same country, culture has a strong effect: 7.2 p.p. more for an increase of 10 points in the home country LFP. On the other hand, when the partners come from different countries, the effect of LFP in wife's home country is about 2.5 p.p. while the effect of LFP in her husband's country is 3.7 p.p.: both these effects are statistically significant and we cannot reject the hypothesis that the effects are equal.

All in all, we find that not only the female's home country culture has an impact on the female's employment choice, but also the cultural background of the husband plays a decisive role. 
Table 3. Female Employment, Partner's Characteristics and Cultural Values in the Origin Country. Probit Estimates

\begin{tabular}{|c|c|c|c|c|}
\hline & (1) & $(2)$ & (3) & (4) \\
\hline Female LFP in Home Country & $\begin{array}{c}0.609 * * * \\
(0.104)\end{array}$ & $\begin{array}{c}0.610^{* * *} \\
(0.101)\end{array}$ & $\begin{array}{l}0.188^{*} \\
(0.105)\end{array}$ & \\
\hline Education & $\begin{array}{l}0.006^{*} \\
(0.003)\end{array}$ & $\begin{array}{l}0.007 * * \\
(0.003)\end{array}$ & $\begin{array}{c}0.010^{* * *} \\
(0.003)\end{array}$ & $\begin{array}{c}0.010 * * * \\
(0.003)\end{array}$ \\
\hline Age & $\begin{array}{c}0.069 * * * \\
(0.009)\end{array}$ & $\begin{array}{c}0.068 * * * \\
(0.009)\end{array}$ & $\begin{array}{c}0.071^{* * *} \\
(0.009)\end{array}$ & $\begin{array}{c}0.071^{* * *} \\
(0.009)\end{array}$ \\
\hline Age Squared & $\begin{array}{c}-0.001 * * * \\
(0.000)\end{array}$ & $\begin{array}{c}-0.001 * * * \\
(0.000)\end{array}$ & $\begin{array}{c}-0.001 * * * \\
(0.000)\end{array}$ & $\begin{array}{c}-0.001 * * * \\
(0.000)\end{array}$ \\
\hline Years of Residence & $\begin{array}{c}0.006^{* * *} \\
(0.001)\end{array}$ & $\begin{array}{c}0.007 * * * \\
(0.001)\end{array}$ & $\begin{array}{c}0.006^{* * *} \\
(0.001)\end{array}$ & $\begin{array}{c}0.007 * * * \\
(0.001)\end{array}$ \\
\hline Children & $\begin{array}{c}-0.064 * * * \\
(0.011)\end{array}$ & $\begin{array}{c}-0.057 * * * \\
(0.011)\end{array}$ & $\begin{array}{c}-0.061 * * * \\
(0.011)\end{array}$ & $\begin{array}{c}-0.062 * * * \\
(0.011)\end{array}$ \\
\hline Partner's Education & $\begin{array}{c}0.008^{* * *} \\
(0.003)\end{array}$ & $\begin{array}{c}0.011^{* * *} \\
(0.003)\end{array}$ & $\begin{array}{c}0.009 * * * \\
(0.003)\end{array}$ & $\begin{array}{c}0.009 * * * \\
(0.003)\end{array}$ \\
\hline Partner's Age & $\begin{array}{c}-0.010 * * * \\
(0.002)\end{array}$ & $\begin{array}{c}-0.010 * * * \\
(0.002)\end{array}$ & $\begin{array}{c}-0.008 * * * \\
(0.002)\end{array}$ & $\begin{array}{c}-0.008 * * * \\
(0.002)\end{array}$ \\
\hline Partner's Income & & $\begin{array}{c}-0.005^{* * *} \\
(0.001)\end{array}$ & $\begin{array}{c}-0.004 * * * \\
(0.001)\end{array}$ & $\begin{array}{c}-0.004 * * * \\
(0.001)\end{array}$ \\
\hline $\begin{array}{l}\text { Female LFP in partner's home } \\
\text { country }\end{array}$ & & & $\begin{array}{c}0.537 * * * \\
(0.101)\end{array}$ & \\
\hline (Same Country)*LFP & & & & $\begin{array}{c}0.724^{* * *} \\
(0.092)\end{array}$ \\
\hline $\begin{array}{l}\text { (Diff. Country)* LFP Wife's } \\
\text { Country }\end{array}$ & & & & $0.248 * *$ \\
\hline $\begin{array}{l}\text { (Diff. Country)* LFP Husband's } \\
\text { Country }\end{array}$ & & & & $\begin{array}{c}(0.101) \\
0.366^{* * *} \\
(0.128)\end{array}$ \\
\hline Observations & 2436 & 2436 & 2436 & 2436 \\
\hline Pseudo R-squared & 0.104 & 0.113 & 0.120 & 0.121 \\
\hline Clusters & 100 & 100 & 100 & 100 \\
\hline
\end{tabular}

Notes: The Table reports marginal effects of Probit estimates (evaluated at the mean values of the explanatory variables in the sample). The dependent variable is Employed. Only married women are considered. In all regressions we control for geographical area dummies (5), city size dummies (3), health status dummies (5) (not reported). Standard errors (corrected for heteroskedasticity and robust to clusters at the country of origin level) are reported in parentheses. The symbols $* * *, * *, *$ indicate that coefficients are statistically significant, respectively, at the 1,5 , and 10 percent level.

\section{Could it be Human Capital or Discrimination?}

If the impact of home country LFP really works through cultural heritage, rather than through some other mechanisms such as human capital, we should find that when immigrants are more integrated in the host country, cultural background should be less important, whereas when immigrants are less integrated and use their home country as a cultural model or reference point, then the role of their cultural values should be more relevant.

To empirically test this aspect we use, in turn, three variables that we believe represent proxies of the strength of the link of immigrants with their home country, and interact them with the Female 
LFP in Home Country. In these regressions, we control for all the variables included in our most complete specification (column 4 of Table 2).

First of all, we build the dummy variable Long Stay equal to one if the years of residence of a woman in Italy are above the median (10) (and 0 otherwise). In Table 4, column (1), we find that the impact of cultural background (measured by a variation of 10 points in the home country LFP) is strong (7.6 p.p.) for females living in Italy by less than 10 years. The effect reduces to about 4.4 p.p. if a female lives in Italy by more than 10 years, suggesting a strong process of assimilation.

Secondly, we also use the answers to the question about the intentions to return to the home country to build a dummy variable Intention to Leave, equal to one in the case a woman plans to leave Italy in the future to go back to her home country. As expected, results in column (2) show that women planning to leave Italy work less (-15.4 p.p.) More importantly, we find that the impact of our cultural proxy is 5.3 p.p. for women not planning to leave, whereas the impact increases to about 9.8 p.p. for those planning to leave, that is, women willing to go back to the home country are strongly related to its cultural values, while those willing to stay in Italy are less responsive to them.

Finally, in column (3) of Table 4 we consider if the immigrant's family has bought a home in Italy (which can be considered a proxy of integration) building the dummy Home Owner. Our estimates show that non-owners are strongly related to their home country's cultural values (7.6 p.p. more in the probability of being employed for an increase of 10 points in the country Female LFP); on the other hand, home-owners react weakly to home country cultural background (2.1 p.p., not statistically significant).

Table 4. Female Employment and Cultural Assimilation. Probit Estimates

\begin{tabular}{lccc} 
& $(1)$ & $(2)$ & $(3)$ \\
\hline \hline Female LFP in Home Country & $0.762^{* * *}$ & $0.529^{* * *}$ & $(0.104)$ \\
Long Stay*LFP & $(0.122)$ & $(0.082)$ & \\
& $-0.315^{* *}$ & & \\
Long Stay & $(0.142)$ & & \\
& $0.163^{* *}$ & $(0.065)$ & $0.455^{* * *}$ \\
LFP*(Intention to Leave) & & $(0.130)$ & $-0.154^{* *}$ \\
& & $(0.070)$ & $-0.548^{* *}$ \\
Intention to Leave & & & $(0.246)$ \\
& & & $0.203^{*}$ \\
Home Owner*LFP & & & $(0.115)$ \\
& & & YES \\
Home Owner & YES & YES & 5131 \\
& 5131 & 4901 & 0.156 \\
\hline Full set of controls & 0.152 & 0.162 & \\
Observations & & & \\
Pseudo R-squared & & & \\
\hline \hline
\end{tabular}

Notes: The Table reports marginal effects of Probit estimates (evaluated at the mean values of the explanatory variables in the sample). The dependent variable is Employed. In all regressions we control for all the variables use in Table 2, column 4 (not reported). Standard errors (corrected for heteroskedasticity and robust to clusters at the country of origin level) are reported in parentheses. The symbols ***, **, * indicate that coefficients are statistically significant, respectively, at the 1,5 , and 10 percent level. 
A possible bias in our estimations of the role of culture could arise from the omission of variables measuring human capital quality (besides the individual years of education) that could be related to the labor force participation in the country of origin. If, for example, countries with low overall quality of human capital accumulation are also countries with low participation in the labor force, then our variable proxying for culture could capture an effect deriving from a low level of human capital, causing an upward bias in the estimation of the coefficient of our interest.

To prevent this kind of distortion we now include in our regressions some variables measuring the quality of human capital in the country of origin.

First, we use the "International Data on Cognitive Skills" provided by Hanushek and Woessmann (2009; Table B3, p. 15) on cognitive skills of students measured in international test scores (average test scores in math and science obtained by primary and secondary school students). We define the variable Quality Human Capital in Home Country as the variable "Cognitive” in Table 3 of Hanushek and Woessmann (2009). Notice that when we merge the Hanushek and Woessmann's data with our data on immigrants in Italy, the sample is reduced to only 61 countries, mainly because data on cognitive skills are not available for all the countries we are considering.

In column (1) of Table 5 we regress Employed only on Female LFP and on Quality Human Capital in Home Country, in column (2) we run the same regression but add our full set of controls (column 4 of Table 2). In both specifications, we do not find any significant effect of the quality of human capital in home country on the probability of being employed. More importantly, when controlling for the quality of human capital the coefficient on Female LFP in Home Country remains positive and highly statistically significant.

As a second measure of human capital, we use the Barro and Lee (2013)'s “Education Attainment Dataset”. Specifically, we use "Education Attainment by 5-year Age Group” and for each country we build the variable Average Years of Schooling (for the year 2000), taking the average of the years of education of women in the age groups from 15 to 44 (data for 98 countries). In columns (3) and (4) (respectively, without and with controls) we run two regressions controlling for Average Years of Schooling. We find that the latter has a positive effect on the probability of being employed when we do not control for the female's own level of education, while this effect disappears when we include individual control variables. The impact of our measure of culture is again positive and statistically significant: the coefficient is 0.51 in the full specification, with a $t$-stat of 4.12.

Finally, as a third indicator of human capital quality in the home country we consider the Product per Worker in the Home Country in the year 2000 from the Penn World Tables (see Heston, Summers and Aten, 2012). We run in columns (5) and (6) two regressions, respectively without and with full controls, controlling for the latter variable. Surprisingly, the coefficient on product per worker in the country of origin is negative in the specification with full controls, implying that immigrants coming from richer countries are less likely to work in Italy (and vice-versa). However, 
the coefficient on our cultural proxy is not changed in magnitude and statistical significance from the inclusion of Product per Worker in Home Country.

Table 5. The Impact of Culture Controlling for the Quality of Human Capital. Probit estimates

\begin{tabular}{|c|c|c|c|c|c|c|c|}
\hline & (1) & $(2)$ & (3) & (4) & (5) & (6) & (7) \\
\hline Female LFP in Home Country & $\begin{array}{c}0.846 * * * \\
(0.217)\end{array}$ & $\begin{array}{c}0.859^{* * *} \\
(0.155)\end{array}$ & $\begin{array}{c}0.547^{* * *} \\
(0.135)\end{array}$ & $\begin{array}{c}0.514^{* * *} \\
(0.125)\end{array}$ & $\begin{array}{c}0.728^{* * *} \\
(0.122)\end{array}$ & $\begin{array}{c}0.490^{* * *} \\
(0.084)\end{array}$ & $\begin{array}{l}0.146 * * \\
(0.065)\end{array}$ \\
\hline $\begin{array}{l}\text { Quality Human Capital in Homє } \\
\text { Country }\end{array}$ & -0.012 & $-0.091^{*}$ & & & & & \\
\hline Average Years of Schooling & & & $\begin{array}{l}0.018 * \\
(0.010)\end{array}$ & $\begin{array}{c}0.002 \\
(0.006)\end{array}$ & & & \\
\hline $\begin{array}{l}\text { Product per Worker in Hom€ } \\
\text { Country }\end{array}$ & & & & & $\begin{array}{c}0.000 \\
(0.000)\end{array}$ & $\begin{array}{c}-0.000 * * * \\
(0.000)\end{array}$ & \\
\hline $\begin{array}{l}\text { Female* Female LFP in Home } \\
\text { Country }\end{array}$ & & & & & & & $\begin{array}{c}0.375^{* * *} \\
(0.096)\end{array}$ \\
\hline Female & & & & & & & $\begin{array}{c}-0.465^{* * * *} \\
(0.038) \\
\end{array}$ \\
\hline Full set of controls & NO & YES & $\mathrm{NO}$ & YES & $\mathrm{NO}$ & YES & YES \\
\hline Observations & 4248 & 4148 & 4998 & 4879 & 5230 & 5107 & 9996 \\
\hline Pseudo R-squared & 0.037 & 0.150 & 0.037 & 0.150 & 0.031 & 0.152 & 0.167 \\
\hline Clusters & 61 & 61 & 98 & 98 & 116 & 116 & 131 \\
\hline
\end{tabular}

Notes: The Table reports marginal effects of Probit estimates (evaluated at the mean values of the explanatory variables in the sample). The dependent variable is Employed. Standard errors (corrected for heteroskedasticity and robust to clusters at the country of origin level) are reported in parentheses. The symbols ***, **, * indicate that coefficients are statistically significant, respectively, at the 1,5 , and 10 percent level.

An alternative mechanism driving our results could be that employers in their hiring decisions are discriminating against individuals coming from countries with low labor market participation. If discrimination were the determinant factor, we should observe that not only females from certain countries are discriminated against, but also males (this is especially true, for example, if discrimination were based on skin color or language spoken). In column (7) of Table 5 we use observations for both males and females and we test if male and female employment participation is affected by their home country cultural background (proxied by LFP). If discrimination is the driving force, we should observe more or less the same effect on men and women. In contrast, we find that the impact on men is 0.14 (significant at 5 percent level), but the effect on females is a much larger 0.52. The difference is 0.37 , highly statistically significant $(t$-stat=3.92). This result suggests that cultural values are probably a more important determinant of women's employment probabilities than ethnic discrimination.

Furthermore, the hypothesis of discrimination would be hard to reconcile with our findings (column 4 in Table 3) that the husband's cultural background (when different from his wife) is strongly affecting the female's employment participation.

Finally, we verify if female LFP in the country of origin has any impact on the wages earned by female immigrants. If the human capital quality were the underlying cause in alternative to culture, we 
should observe that among employed women those coming from high LFP countries earn higher wages and vice versa.

We take the logarithm of labor income and run some OLS regressions (in the spirit of Mincerian equations) controlling for standard determinants of wages (hours worked, education, age, years in Italy, areas of residence, etc.). Results are reported in Table 6. While all the coefficients have the expected sign and are consistent with the findings of the labor economics literature, we find that Female LFP in the Home Country has no effect at all on female earnings. In all specifications, the coefficient is not significant (and it is negative).

The fact the female LFP in the origin country has a strong effect on the women's employment probabilities while has no effect on wages reinforces our hypothesis that it is the cultural background that has an impact on women's labor market outcomes.

Table 6. The Impact of Culture on Wages. Dependent Variable: Log(Wage)

\begin{tabular}{|c|c|c|c|}
\hline & (1) & $\overline{(2)}$ & (3) \\
\hline \multirow[t]{2}{*}{ Female LFP in Home Country } & -0.051 & -0.023 & -0.040 \\
\hline & $(0.059)$ & $(0.059)$ & $(0.057)$ \\
\hline \multirow[t]{2}{*}{ Hours Worked } & $0.017 * * *$ & $0.017 * * *$ & $0.016 * * *$ \\
\hline & $(0.001)$ & $(0.001)$ & $(0.001)$ \\
\hline \multirow[t]{2}{*}{ Education } & $0.013 * * *$ & $0.011^{* * *}$ & $0.011^{* * *}$ \\
\hline & $(0.004)$ & $(0.004)$ & $(0.004)$ \\
\hline \multirow[t]{2}{*}{ Age } & $0.015^{* * *}$ & $0.011 * *$ & $0.014 * * *$ \\
\hline & $(0.005)$ & $(0.004)$ & $(0.004)$ \\
\hline \multirow[t]{2}{*}{ Age Squared } & $-0.000 * * *$ & $-0.000 * *$ & $-0.000 * * *$ \\
\hline & $(0.000)$ & $(0.000)$ & $(0.000)$ \\
\hline \multirow[t]{2}{*}{ Years of Residence } & $0.008 * * *$ & $0.007 * * *$ & $0.007 * * *$ \\
\hline & $(0.002)$ & $(0.002)$ & $(0.002)$ \\
\hline \multirow[t]{2}{*}{ North-East } & -0.020 & -0.029 & -0.028 \\
\hline & $(0.021)$ & $(0.020)$ & $(0.020)$ \\
\hline \multirow[t]{2}{*}{ Centre } & $-0.084 * * *$ & $-0.068 * * *$ & $-0.068 * * *$ \\
\hline & $(0.028)$ & $(0.025)$ & $(0.025)$ \\
\hline \multirow[t]{2}{*}{ South } & $-0.196 * * *$ & $-0.174 * * *$ & $-0.179 * * *$ \\
\hline & $(0.021)$ & $(0.020)$ & $(0.020)$ \\
\hline \multirow[t]{2}{*}{ Islands } & $-0.161^{* * *}$ & $-0.135 * * *$ & $-0.139 * * *$ \\
\hline & (0.033) & $(0.031)$ & $(0.031)$ \\
\hline \multirow[t]{2}{*}{ Large City } & $0.048^{* * *}$ & $0.054 * * *$ & $0.050 * * *$ \\
\hline & $(0.015)$ & $(0.014)$ & $(0.014)$ \\
\hline \multirow[t]{2}{*}{ Small City } & $0.039 *$ & $0.042^{*}$ & $0.041^{*}$ \\
\hline & $(0.023)$ & $(0.022)$ & $(0.023)$ \\
\hline \multirow[t]{2}{*}{ Firm Size } & & $0.001 * * *$ & $0.001 * * *$ \\
\hline & & $(0.000)$ & $(0.000)$ \\
\hline \multirow[t]{2}{*}{ Married } & & & $-0.037 * *$ \\
\hline & & & $(0.017)$ \\
\hline \multirow[t]{2}{*}{ Children } & & & $-0.014^{*}$ \\
\hline & & & $(0.008)$ \\
\hline \multirow[t]{2}{*}{ Constant } & $5.172 * * *$ & $5.200 * * *$ & $5.175^{* * *}$ \\
\hline & $(0.303)$ & $(0.294)$ & $(0.299)$ \\
\hline Observations & 2491 & 2491 & 2491 \\
\hline R-squared & 0.319 & 0.345 & 0.348 \\
\hline
\end{tabular}

Notes: The Table reports OLS estimates. The dependent variable is Log(Wage). Sample: all employed women. Standard errors (corrected for heteroskedasticity and robust to clusters at the country of origin level) are reported in parentheses. The symbols $* * *, * * *$ indicate that coefficients are statistically significant, respectively, at the 1,5 , and 10 percent level. 


\section{Some Robustness Checks}

In this section we carry out a number of checks to verify if our results are robust to different definitions of the main variables, different samples and different estimation strategies.

First of all, instead of using the dummy Employed we use as dependent variable the number of hours worked on average in a week (as in Fernández and Fogli, 2009), using the OLS estimator. In columns (1) and (2) of Table 7 we find that an increase of 10 percentage points in female LFP increases the hours worked of 2.7 (without controls) or by 1.5 (with the full range of controls) ( $t$ stat=4.5), corresponding to about $8 \%$ of the mean of the dependent variable.

In columns (3) and (4) we use the dummy "In Labor Force" (equal to one if an individual is employed or unemployed and searching for a job) and we find similar effects of those found when we used Employed.

In columns (5) and (6) we use as dependent variable Employed but instead of using a Probit estimator we use a Linear Probability Model. Again, the results are widely confirmed.

Table 7. Robustness Checks: Different Definitions of the Dependent Variable

\begin{tabular}{lcccccc}
\hline & $\begin{array}{c}(1) \\
\text { Hours } \\
\text { Worked }\end{array}$ & $\begin{array}{c}\text { Hours } \\
\text { Worked }\end{array}$ & $\begin{array}{c}\text { In Labor } \\
\text { Force }\end{array}$ & $\begin{array}{c}\text { (4) } \\
\text { In Labor } \\
\text { Force }\end{array}$ & $\begin{array}{c}\text { (5) } \\
\text { Employed }\end{array}$ & $\begin{array}{c}(6) \\
\text { Employed }\end{array}$ \\
\hline Female LFP in Home Country & $27.35^{* * *}$ & $14.96^{* * *}$ & $0.580^{* * *}$ & $0.338^{* * *}$ & $0.719^{* * *}$ & $0.424^{* * *}$ \\
& $(3.300)$ & $(3.339)$ & $(0.0981)$ & $(0.0575)$ & $(0.110)$ & (0.0736) \\
\hline Full set of controls & NO & YES & NO & YES & NO & YES \\
Observations & 5254 & 5131 & 5254 & 5131 & 5254 & 5131 \\
$\begin{array}{l}\text { Adjusted R-squared } \\
\text { Pseudo R-squared }\end{array}$ & 0.042 & 0.188 & & & 0.043 & 0.191 \\
\hline \hline
\end{tabular}

Notes: The Table reports marginal effects of Probit estimates (evaluated at the mean values of the explanatory variables in the sample) in columns (3)-(4) and OLS coefficients in columns (1), (2), (5) and (6). The dependent variable is reported on the top of each column. Standard errors (corrected for heteroskedasticity and robust to clusters at the country of origin level) are reported in parentheses. The symbols ***,**,* indicate that coefficients are statistically significant, respectively, at the 1,5 , and 10 percent level.

In Table 8 we report estimates carrying out further robustness checks. In columns (1) and (2) we focus only on females of restricted ranges of age, females from 25 to 50 years old (column 1) and from 30 to 40 years old (column 2), using in both cases the full range of controls. We again find very similar effects (0.51) to those found above.

In column (3) we use observations only from countries with at least 10 immigrants in our sample, while in column (4) we only use observations from countries with at least 20 immigrants. The estimates are almost the same as in previous specifications.

In column (5) of Table 8 we exclude from our sample Italian women (285 who are present in our sample because they are married to immigrants). In column (6) we estimate our main regression excluding women that declare to be still at school. In both cases, the estimated coefficient remain almost unchanged. 
Finally, in columns (7) and (8) we use the Female LFP in the country of origin averaged over the period 1990-1999 and over the period 2000-2009, respectively. Coefficients turn out to be similar (higher in magnitude). This is consistent with the idea that culture is a rather persistent phenomenon, transmitted fairly unchanged from generation to generation.

Table 8. Robustness Checks: Different Samples and Different Definitions of LFP

\begin{tabular}{|c|c|c|c|c|c|c|c|c|}
\hline & (1) & (2) & (3) & (4) & (5) & $(6)$ & (7) & (8) \\
\hline Female LFP in Home & $0.510 * * *$ & $0.505 * * *$ & $0.524 * * *$ & $0.544^{* * *}$ & $0.501 * * *$ & $0.522 * * *$ & & \\
\hline & $(0.106)$ & $(0.121)$ & $(0.0874)$ & $(0.0892)$ & $(0.0860)$ & $(0.0874)$ & & \\
\hline $\begin{array}{l}\text { Female LFP in Home } \\
\text { Country } 1990-99\end{array}$ & & & & & & & $0.636^{* * *}$ & \\
\hline $\begin{array}{l}\text { Female LFP in Home } \\
\text { Country 2000-09 }\end{array}$ & & & & & & & $(0.0892)$ & $\begin{array}{l}0.690 * * * \\
(0.0865) \\
\end{array}$ \\
\hline Full set of controls & YES & YES & YES & YES & YES & YES & YES & YES \\
\hline Observations & 3938 & 1905 & 4994 & 4837 & 4848 & 4899 & 5131 & 5131 \\
\hline Pseudo R-squared & 0.139 & 0.138 & 0.154 & 0.155 & 0.160 & 0.151 & 0.153 & 0.152 \\
\hline
\end{tabular}

Notes: The Table reports marginal effects of Probit estimates (evaluated at the mean values of the explanatory variables in the sample). Standard errors (corrected for heteroskedasticity and robust to clusters at the country of origin level) are reported in parentheses. The symbols $* * *, * *, *$ indicate that coefficients are statistically significant, respectively, at the 1,5 , and 10 percent level.

\section{Is Cultural Influence Driven by Religion?}

An important part of cultural values is interconnected with religious beliefs. With different attitudes towards gender role models and the appropriate role for women in society, different religions might strongly affect women's decisions of working, investing in human capital, having children and so on.

A number of papers has shown the importance of religion for economic outcomes at micro and macro level (Guiso, Sapienza and Zingales, 2003 and 2006; Barro and McCleary, 2002; Iannaccone, 1998).

In this Section we verify if our results on the importance of cultural heritage for economic behaviors are driven exclusively by religious beliefs or if cultural background beyond religion has an additional effect on labor market decisions. More precisely, we check if female immigrants coming from countries with different religions show different propensities to work and whether, controlling for the type of prevailing religion, other cultural values affect labor force participation.

Unfortunately, in our dataset we do not observe directly the religion (if any) professed by interviewed individuals. Using the data provided by the Association of Religion Data Archives (ARDA) we observe the most widespread religion in each country and impute to each immigrant the prevailing religion in her country. 
The immigrants in our sample come from countries practicing the following major religions: Muslim (32\%), Orthodox (29\%), Catholic (29\%), Buddhist (5.5\%), Hindu (2.7\%). We build a dummy variable for each of these religions.

To evaluate the impact of religion on employment decisions we run our main regressions controlling for the set of dummies for religion (leaving Catholics as reference category). Results are reported in Table 9. In column (1) we only use Female LFP in Home Country as independent variable, in addition to religion dummies. In column (2) we use the full set of individual characteristics (see column 3 of Table 2). In column (3) we also control for Married and Children.

All in all, we find that immigrants coming from Muslim countries are much less likely to work, showing a lower probability of being employed ranging from -9 to -24 p.p. according to the specification. This result is consistent with the findings of Guiso, Sapienza and Zingales (2003). Orthodox Christians are slightly more likely to work than Catholics while females coming from Buddhist or Hindu countries are not significantly different in terms of work decisions from the reference category. An F-test on joint significance of religion dummies confirm that religion is important in explaining female working decisions.

More importantly, the coefficient on the variable capturing cultural values - although lower in magnitude - is positive and statistically significant when controlling for the religion of the home country. Therefore, we find that considering immigrants coming from countries with the same religion, a higher female LFP of 10 points increases the probability of working of about 2.8 points. Cultural values seem to affect female decisions in addition to religious beliefs, although a considerable part of the cultural background effect is imputable to religion.

In column (4) of Table 9 we focus only on married females and control for husband's characteristics. We find again that females from Muslim counties are less likely to work (-13 p.p.) but the Female LFP in the origin country has a strong impact (0.46), significant at the 1 percent level. In column (5) we also control for the religion of the husband's country. ${ }^{8}$ We find again very similar results: religion is an important determinant of labor force decisions, but cultural values remain important also when religion is taken into account.

\footnotetext{
${ }^{8}$ We need to omit some dummies in this specification due to multicollinearity problems, since very often the religion of husband's and wife's countries coincide.
} 
Table 9. Cultural Values and the Role of Religion for Women's Employment Decisions

\begin{tabular}{|c|c|c|c|c|c|}
\hline & (1) & (2) & (3) & (4) & (5) \\
\hline Female LFP in Home Country & $\begin{array}{c}0.270^{* *} \\
(0.117)\end{array}$ & $\begin{array}{c}0.280^{* *} \\
(0.116)\end{array}$ & $\begin{array}{c}0.281^{* *} \\
(0.119)\end{array}$ & $\begin{array}{c}0.456^{* * *} \\
(0.147)\end{array}$ & $\begin{array}{c}0.447 * * * \\
(0.149)\end{array}$ \\
\hline Muslim & $\begin{array}{c}-0.241 * * * \\
(0.042)\end{array}$ & $\begin{array}{c}-0.187 * * * \\
(0.042)\end{array}$ & $\begin{array}{c}-0.087^{*} \\
(0.048)\end{array}$ & $\begin{array}{c}-0.134^{* *} \\
(0.060)\end{array}$ & $\begin{array}{c}-0.056 \\
(0.054)\end{array}$ \\
\hline Orthodox Christian & $\begin{array}{c}0.047 \\
(0.049)\end{array}$ & $\begin{array}{c}0.065 \\
(0.042)\end{array}$ & $\begin{array}{c}0.043 \\
(0.044)\end{array}$ & $\begin{array}{c}-0.055 \\
(0.053)\end{array}$ & $\begin{array}{c}-0.058 \\
(0.053)\end{array}$ \\
\hline Buddhist & $\begin{array}{l}-0.044 \\
(0.041)\end{array}$ & $\begin{array}{c}0.003 \\
(0.050)\end{array}$ & $\begin{array}{c}0.077 \\
(0.057)\end{array}$ & $\begin{array}{c}0.026 \\
(0.070)\end{array}$ & $\begin{array}{c}0.018 \\
(0.071)\end{array}$ \\
\hline Hindu & $\begin{array}{c}-0.101 \\
(0.170)\end{array}$ & $\begin{array}{c}-0.083 \\
(0.157)\end{array}$ & $\begin{array}{c}0.003 \\
(0.144)\end{array}$ & $\begin{array}{c}-0.034 \\
(0.114)\end{array}$ & $\begin{array}{c}-0.043 \\
(0.113)\end{array}$ \\
\hline Partner: Muslim & & & & & $\begin{array}{r}-0.095^{* * *} \\
(0.037) \\
\end{array}$ \\
\hline Full set of controls & $\mathrm{NO}$ & YES & YES & YES & YES \\
\hline Controls husband's variables & NO & NO & NO & YES & YES \\
\hline Observations & 5254 & 5131 & 5131 & 2436 & 2436 \\
\hline Pseudo R-squared & 0.057 & 0.093 & 0.156 & 0.121 & 0.122 \\
\hline
\end{tabular}

Notes: The Table reports marginal effects of Probit estimates (evaluated at the mean values of the explanatory variables in the sample). Standard errors (corrected for heteroskedasticity and robust to clusters at the country of origin level) are reported in parentheses. The symbols ***, **, * indicate that coefficients are statistically significant, respectively, at the 1,5 , and 10 percent level.

\section{Concluding Remarks}

Cultural values seem to play a significant role in economic outcomes but, until recently, it has been hard to prove empirically that culture causes economic behaviors. A recent promising empirical strategy is the epidemiological approach, relating immigrants' behavior in the host country (within a uniform economic and institutional environment) with economic or social patterns observed in the origin country. However, the evidence gathered so far by the epidemiological approach is almost exclusively based on the US or Canadian immigrants.

Following the epidemiological approach, in this paper we have investigated how cultural values from the home country affect work decisions of female immigrants in Italy, using the ISTAT National Survey of Households with Immigrants.

Since Italy is a recent immigration country, we have used data on first generation immigrants. Although, from the one hand, this could lead to some estimation problems (due to language barriers and other shocks hitting immigrants when they first move to a foreign country), on the other hand first generation immigrants allow us to capture cultural influence that have occurred through a wider variety of channels (parents, schools, friends, neighbors, social groups, etc.) and that are less affected by assimilation processes with the natives. A further advantage of using data on Italian immigrants is that the latter come from a large number of countries (118) and from all geographical areas, with very different cultural background and religious beliefs.

We relate the probability of being employed in Italy for immigrant women with the female labor force participation in the country of origin, taken as a proxy of cultural heritage and gender role 
model. Controlling for a number of individual and household characteristics, we have shown that participation in the labor market is affected by the culture of women's origin countries. In our preferred specification, an increase of 10 points in the female labor force participation in the origin country increases the employment probability of women in Italy of about 5 percentage points. This is a remarkable effect, confirming the importance of cultural values in shaping economic outcomes. Subsequently, we have shown that also the culture of the husband's country (measured analogously with the female LFP in his home country) is at least as important in defining women's economic behavior.

We have also shown that the relationship between work decisions in the host country and home country LFP cannot be attributed to human capital quality or ethnic discrimination and it turns out to be stronger for immigrants that maintained more intense ties with their origin countries.

Finally, we have investigated to what extent cultural influence is driven by religious beliefs, finding that religion is a key determinant of differences in female labor decisions, but, besides religion, other cultural values exert additional influence.

\section{References}

Alesina, A., Giuliano, P. (2011). "Family ties and political participation”. Journal of the European Economic Association, 9(5): 817-839.

Antecol, H. (2000). "An examination of cross-country differences in the gender gap in labor force participation rates”, Labour Economics 7: 409-426.

Barro, R., Lee, J.-W. (2013). "A New Data Set of Educational Attainment in the World, 1950-2010”. Journal of Development Economics, vol 104: 184-198.

Barro, R., McCleary R. M. (2002). "Religion and Political Economy in an International Panel”, NBER Working Paper No. 8931

Blau F. D., Kahn L. M., Liu A. Y-H., Papps K. L. (2013), “The transmission of women’s fertility, human capital, and work orientation across immigrant generations”. Journal of Population Economics 26: 405-435.

Carroll, C, B. Rhee, and C. Rhee. (1994). "Are there cultural differences on saving? Some crosscountry evidence”, Quarterly Journal of Economics, Vol. 109(3): 685-700

Fernández R. (2007). "Women, Work, and Culture”, Journal of the European Economic Association, 5 (2-3): 305-332.

Fernández R. (2011). “Does Culture Matter?”, In Benhabib, J., Jackson, M. O., and Bisin, A. (Editors), Handbook of Social Economics, 481-510. The Netherlands: North-Holland.

Fernández R., Fogli A. (2009). "Culture: An empirical investigation of beliefs, work and fertility", American Economic Journal: Macroeconomics, 1(1): 146-177.

Fisman, R., Miguel, E. (2007). "Corruption, Norms and Legal Enforcement: Evidence from Diplomatic Parking Tickets”. Journal of Political Economy 115 (6): 1020-1048.

Gevrek E.Z., Gevrek D., Gupta S. (2013). “Culture, Intermarriage, and Immigrant Women’s Labor Supply”. International Migration, 51(6): 146-167.

Giuliano P. (2007). "Living arrangements in Western Europe: does cultural origin matter?” Journal of the European Economic Association, 5(5): 927-952

Guiso L., Sapienza P., Zingales L. (2006). “Does culture affect economic outcomes?”. Journal of Economic Perspectives, 20 (2): 23-48. 
Guiso, L., Sapienza, P., Zingales, L. (2003). "People's opium? Religion and economic attitudes”, Journal of Monetary Economics, Elsevier, vol. 50(1): 225-282

Hanushek, E., Woessmann, L. (2009). "Do Better Schools Lead to More Growth? Cognitive Skills, Economic Outcomes, and Causation”, NBER Working Paper No. 14633

Heston, A. Summers, R. and Aten, B., (2012). Penn World Table Version 7.1, Center for International Comparisons of Production, Income and Prices at the University of Pennsylvania.

Iannaccone, L.R. (1998). "Introduction to the economics of religion”. Journal of Economic Literature 36 (3): 1465-1496.

International Labor Organization (ILO). Database of Labor Statistics. http://laborsta.ilo.org/

Istat (2009). Italian Statistics on Income and Living Conditions of Households with Foreigners

Istat (2011). "Le famiglie con stranieri: indicatori di disagio economico". Serie Statistiche in breve. 28 febbraio 2011. 